\title{
O sistema territorial turístico: uma análise dos subsistemas de fluxos e fixos no município de Jaboatão dos Guararapes
}

\section{The territorial touristic system: an analysis for the sub-systems of flow and settled of the municipal district of Jaboatão dos Guararapes}

\author{
Francisco Antônio dos Anjos (ANJOS, F. A.) ${ }^{*} \mathrm{e}$ \\ Lina Juliana Tavares Viana (VIANA, L. J. T.) ${ }^{* *}$
}

\begin{abstract}
RESUMO: Esse artigo compreende uma análise do município de Jaboatão dos Guararapes, pertencente ao Estado de Pernambuco, localizado na região Nordeste do Brasil, por meio de uma abordagem metodológica, a partir do modelo de Sistema Territorial Turístico, compreendido pelos subsistemas de fluxos e fixos, os quais são constituídos por elementos naturais e construídos pelo homem. Como o processo de territorialização objetiva criar vínculos entre o objeto (o sistema) e a ação (o processo), os procedimentos metodológicos desenvolvidos nesse artigo apresentam-se formatados por meio de pesquisas de dados primários e secundários, resultando no desenvolvimento de um sistema de informações. A relação entre os elementos dos subsistemas dos fixos e das dinâmicas dos subsistemas dos fluxos realizadas permite a compreensão das interrelações entre os elementos do sistema.
\end{abstract}

Palavras-chave: Planejamento Turístico; Sistema Territorial; Subsistemas de Fluxos e Fixos.

ABSTRACT: This article comprises of an analysis of the municipal district of Jaboatão dos Guararapes, in Pernambuco, located in Brazilian northeastern, by means of a methodologial approach, from the model of the Territorial Touristic System, comprehended by the sub-systems of flow and settled, which ones, are composed by natural elements and constructed by the men. As the procces of territorialization objectify creating entailments between the object (the system) and the action (the procces), the methodological procedure developed in this article presentate in itself formated by mean of researches of primary and secondary informations, resulting in a development of system information. The relation between the sub-systems elements of settled and the dynamics of the sub-sysistems of the flow consummated allow the comprehension of the inter-report between the system elements.

Key words: Planing Touristic; Territorial System; Sub-Systems of Flow and Settled.

\footnotetext{
* Doutor em Engenharia da Produção (Gestão Ambiental). Professor e pesquisador do Programa de PósGraduação Strictu sensu Mestrado Acadêmico em Turismo e Hotelaria e do Doutorado em Administração e Turismo da Universidade do Vale do Itajaí - UNIVALI. Endereço: $5^{\text {a }}$ avenida, s. n. - Bairro dos Municípios - Balneário Camboriú - SC. Telefone: (47) 3261-1211.E-mail: anjos@univali.br

** Bacharel em Turismo e Hotelaria e aluna do Programa de Pós-Graduação Strictu sensu Mestrado Acadêmico em Turismo e Hotelaria da Universidade do Vale do Itajaí - UNIVALI. Endereço: Rua Antonio Valdevino Costa 280 (ap. 104) - Bairro Cordeiro - Recife - Pernambuco. CEP: 50640-040. Telefones: (81) 3228-9731/(81)9717-5460.E-mail: jujutviana@ hotmail.com
} 


\section{INTRODUÇÃO}

O desenvolvimento acelerado das cidades modifica o espaço e produz o surgimento desordenado de construções e ocupações, resultando em graves problemas para a população e para a organização social. $\mathrm{O}$ estudo sobre a continuidade do processo de desenvolvimento dos centros urbanos é fundamental para compreender a formação das cidades, que ocorre através da organização do território e se molda pela necessidade da forma de utilização que lhe é dada.

Esses fatores tornam-se perceptíveis ao longo dos anos, pois o processo de modernização desses lugares apresenta-se como uma resposta aos interesses de uso das cidades, apontando tendências a modificações que transformam o seu contexto espacial para satisfazer as necessidades dos indivíduos que utilizam esses espaços, esses indivíduos são identificados como moradores, turistas e visitantes.

A implantação de uma infra-estrutura adequada, para suportar essas necessidades apresentadas pelo dinamismo da economia e da sociedade é definida pelo desenvolvimento e expansão do território. As funções de um novo espaço geográfico, vão se configurando através dos movimentos da população, juntamente à extensão da cidadania, da distribuição da agricultura, da indústria e dos serviços, uma estrutura que necessita da inclusão da legislação civil, fiscal e financeira para dar suporte ao processo desse desenvolvimento (SANTOS E SILVEIRA, 2005).

Desse modo pode-se dizer que o crescimento de alguns setores como o de hospedagens, alimentos e bebidas e transportes, junto à consolidação e a formação de uma classe consumidora de produtos turísticos, deu origem a diferentes fluxos, resultando em uma nova ordem no processo de ocupação do espaço, observando que cada vez há menos território sem turistas (TELES, 2006).

Ao trabalhar o planejamento turístico, a localidade deve se preocupar também com a produção de espaços e atividades que atendam aos anseios tanto da população local, quanto dos turistas. Porém sua implantação é observada a partir de dois objetivos conflitantes: prover oportunidades e acessos às experiências recreacionais atingindo o maior número de pessoas possível e a proteção que evite a descaracterização dos locais privilegiados pela natureza e pelo patrimônio cultural nas comunidades (RUSCHMANN, 2004). 
A implantação do planejamento em uma localidade depende do interesse do poder público e da população local, desse modo à atuação do Estado deve se sobrepor aos problemas apresentados, se fossem vistos a partir de um conjunto de fatores que precisam ser trabalhados simultaneamente. As atuações apresentadas podem ser compreendidas a partir das perspectivas do planejamento territorial que permite constituir uma forma de aproximação da realidade existente a uma realidade desejada e do planejamento sistêmico que permite identificar padrões e inter-relações entre variáveis que possibilitam melhor entendimento do fenômeno estudado (SCHÄFER, e ANJOS, 2007).

Diante do exposto, percebe-se que a presente análise do espaço turístico para o planejamento, precisa abranger os subsistemas de fixos e dos fluxos. Os fixos são entendidos como os elementos naturais, cujas dinâmicas são resultantes de processos ecológicos integrantes do sistema natural, e controlados por dinâmicas não humanas e os elementos construídos, resultantes das ações humanas sobre os espaços (materializações das produções humanas). Os fluxos compreendem as dinâmicas sócioculturais onde envolvem a relação do homem com os sistemas ecológicos, econômicos e o próprio sistema social, as dinâmicas econômicas compostas por dinâmicas relacionadas à produção, distribuição, consumo e acumulação do capital. Tal subsistema é formado por um conjunto de organizações que atuam, ora para atender o residente, ora o turista (ANJOS, 2004).

Observando essa abordagem, define-se então a organização espacial de uma região turística, através da territorialização e da urbanização de uma localidade, considerando que a configuração territorial se constitui num conjunto de complexos naturais, formado pelas obras do homem. Desse modo será apresentando neste artigo a análise dos subsistemas de fluxos e fixos que envolvem o sistema territorial turístico do município de Jaboatão dos Guararapes. 


\section{O SISTEMA TERRITORIAL TURÍSTICO NA BUSCA DA COMPREENÇÃO DOS FENÔMENOS SOCIAIS}

Ao desenvolver uma estrutura teórica, unificada e sistêmica, Capra (2002) apresenta um diagrama de quatro perspectivas forma, processo, significado e matéria de modo que visa a compreender os fenômenos sociais.

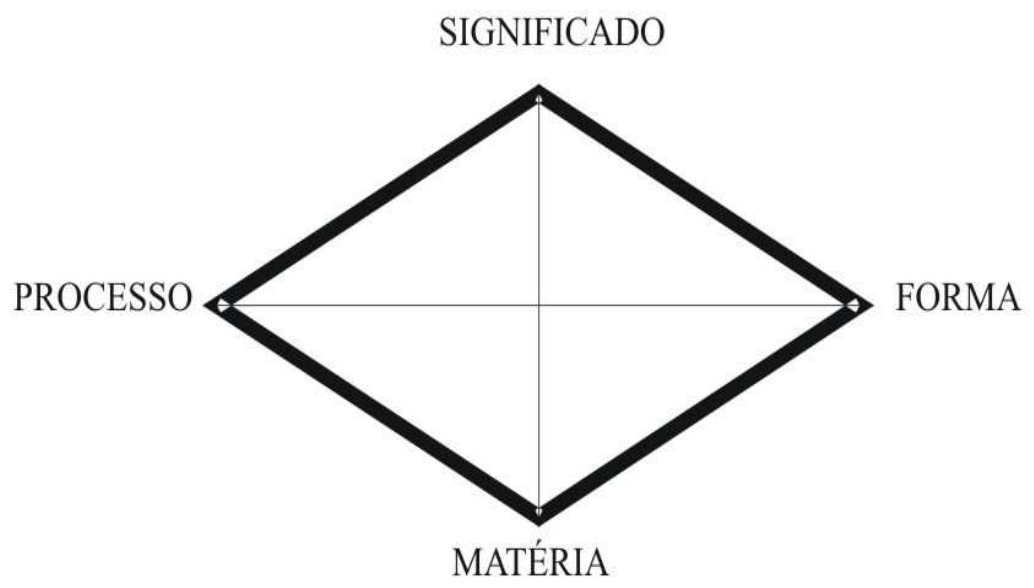

Figura 1: A compreensão dos fenômenos sociais

Fonte: CAPRA, 2002, p. 86.

Ao compreender a realidade social permeada por valores culturais Capra (2002, p.87) explica a cultura, por meio da criação de uma rede (forma) de comunicação (processo) onde se gera o significado, que será transmitido por gerações através de artefatos e textos escritos (matéria). Essa realidade social está atrelada a uma consciência reflexiva, diretamente ligada à compreensão da linguagem e do contexto social (CAPRA, 2002, p. 86).

[...] a autoconsciência surgiu na evolução dos nossos antepassados junto com a linguagem, o pensamento conceitual e o mundo social dos relacionamentos organizados e da cultura $[\ldots]$

As inter-relações tornam-se perceptíveis a partir da mudança estrutural de um padrão que vai se adequar de acordo com cada situação. Embora esses padrões se 
modifiquem, a materialização de uma nova estrutura é compreendida pelos processos subjacentes que organizam o padrão e originam essa estrutura materializada.

Essas inter-relações estruturais surgem a partir de interferências dinâmicas que vão se moldando de acordo com cada estrutura, ocasionando as mudanças no sistema. As relações formam estruturas sistêmicas de características essenciais do todo integrado e dinâmico, características essas que não estão totalmente nas partes, mas nos relacionamentos dinâmicos entre elas, entre elas e o todo, entre o todo e outros todos (ANDRADE, et. $A l, 2006$ ).

A compreensão sistêmica para Capra $(2002$, p. 93) supõe que a vida é dotada de uma unidade fundamental, aonde os diversos sistemas vivos apresentam padrões de organizações semelhantes. Justificando desse modo as suas afirmações ao dizer que "à medida que a vida evolui, esses padrões tendem a tornar-se cada vez mais elaborados; mas nem por isso deixam de ser variações sobre os mesmos temas".

Ambos configuram a integração entre as partes dinâmicas de características integradas que apresentam padrões e organizações semelhantes. A relação dinâmica entre a evolução e a elaboração dos padrões define o dinamismo entre as partes, o todo, e outros todos, como variações de um mesmo objeto. A aplicação da compreensão sistêmica da vida ao domínio social identifica-se à aplicação dos conhecimentos relacionados aos padrões e princípios básicos de organizações da vida, em especifico, da compreensão das redes vivas, como a realidade social (ANDRADE et. Al, 2006, CAPRA, 2002).

Para estabelecer a relação entre a teoria dos sistemas e o estruturalismo podemse entender as ações humanas não funcionais, sendo imprescindíveis para a existência da sociedade. A teoria dos sistemas é definida como a compreensão que entende o mundo enquanto um organismo social na sua totalidade, sendo a sociedade um todo funcional formado por partes que são os sistemas, essa percepção do complexo grupo social, sempre em interação, produzindo ações e reações. (PANOSSO NETTO, 2005).

Para Anjos (2004) o processo de territorialização tem por principal objetivo desenvolver ações que visem o aperfeiçoamento da conscientização coletiva, bem como da cooperação e o consenso entre os agentes integrantes dos sistemas. Ao conceber que somente processos que estão ligados aos seus ambientes por vínculos estruturais são 
sistemas que aprendem o processo de territorialização objetiva criar tais vínculos entre o objeto (o sistema) e a ação (o processo).

O processo está dividido em: pesquisa de dados primários; pesquisas de dados secundários e desenvolvimento de um sistema de informações. Nesse processo, a pesquisa de dados primários apresenta-se relacionada a elementos dos subsistemas dos fixos e das dinâmicas dos subsistemas dos fluxos; os dados secundários a lacunas deixadas pelos dados primários e o sistema de informações ao caráter territorial e a disponibilidade com todos os membros envolvidos (ANJOS, 2004).

Com uma percepção muito próxima, Rodrigues (1997, p. 62) compreende o espaço do turismo como fluido pela sua natureza de grande mobilidade horizontal e vertical. Também considerando os fixos e os fluxos como componentes do sistema a partir da relação entre os centros emissores da demanda, de onde partem os fluxos para os núcleos receptores.

\section{ANÁLISE DOS SUBSISTEMAS DE FLUXOS E FIXOS NO MUNICÍPIO DE JABOATÃO DOS GUARARAPES.}

A análise apresentada será avaliada de acordo com o quadro de sistemas de Anjos (2004, p. 154) que afirma que "o objetivo central deste processo é compreender a dinâmica do sistema territorial turístico, possibilitando o desenvolvimento de um sistema de informação geográfico - SIG que dê suporte aos demais processos, através de atualização permanente dos dados".

O sistema deve ser entendido de duas formas o subsistema dos residentes e dos turistas. Desta forma, cada subsistema deve ser analisado na sua particularidade e nas suas relações, buscando perceber as especificidades, dinâmicas e sobreposições (de escalas espaciais e temporais) entre os dois subsistemas. (ANJOS, 2004).

O modelo de planejamento e gestão de territórios turísticos é composto de processos integrados, que possuem dinâmicas próprias, e ao mesmo tempo em que estão contidos em processos mais abrangentes. O modelo proposto é representado por um macro-processo, composto de cinco processos: territorialização, leitura do sistema, definição das estratégias de perturbação, implantação e viabilização e monitoramento e avaliação. Esses cinco processos apresentam-se em formação de redes, mantendo a 
perspectiva sistêmica do modelo, com uma integração entre os processos. Os cinco processos integrados serão apresentados nos próximos itens quanto a sua abrangência, objetivos, agentes e indicadores (Figura 2).

\section{PLANEJAMENTO E GESTÃO DE TERRITÓRIO TURÍSTICO}

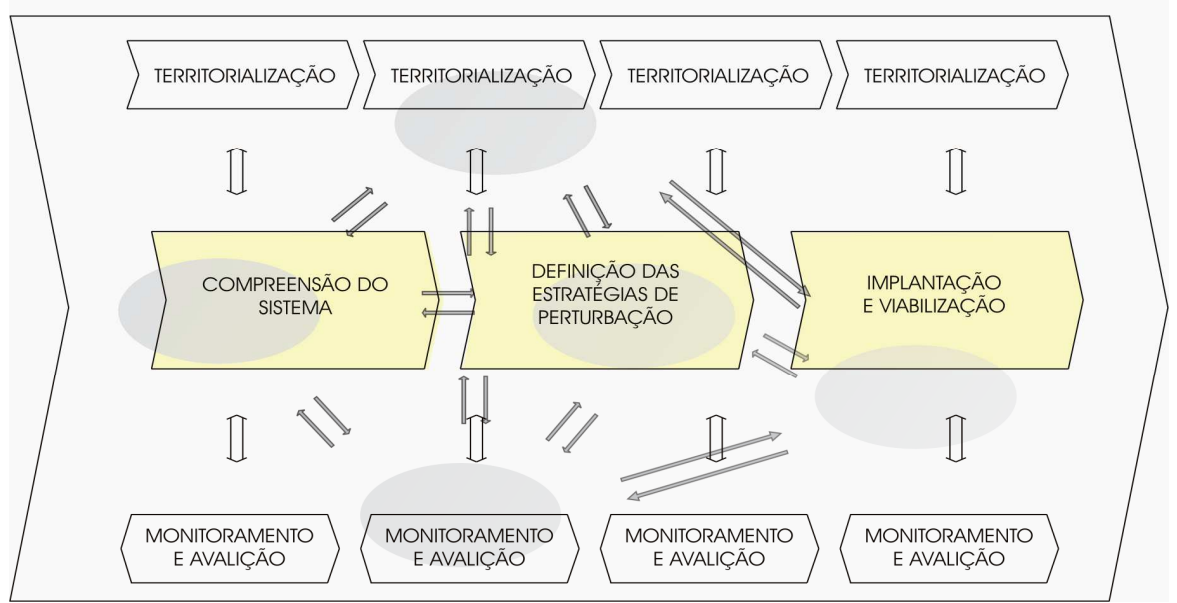

Figura 2: Representação do processo de planejamento e gestão de territórios turísticos Fonte: Anjos, 2004, p. 141

As saídas nos processos se constituem em entradas para outros processos, mantendo um ciclo de melhorias contínuas permanentes. O ciclo de melhoria dar-se-á em cada processo e no macro-processo, configurando sempre situações novas de entrada e saída. As entradas serão constituídas de ações que possibilitem perturbar o estado em que se encontra o território em foco (sociedade, economia ou ambiente), visando criar uma nova territorialidade.

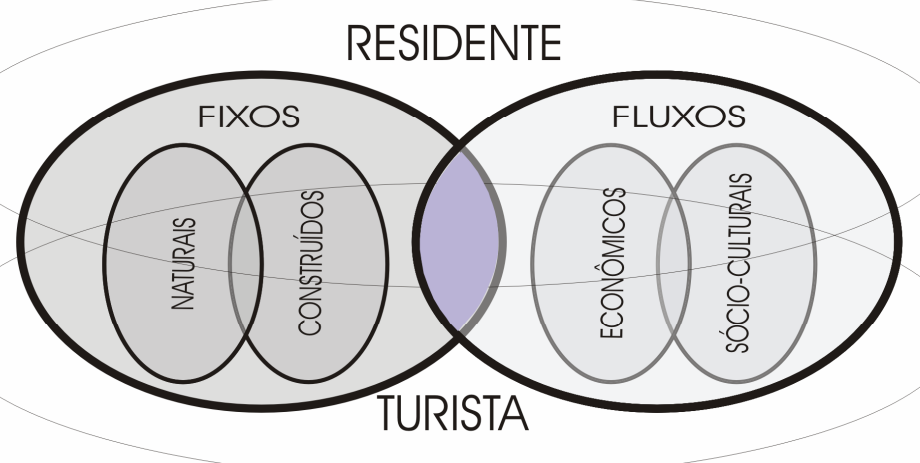

Figura 3: Sistema Territorial Turístico

Fonte: Anjos 2004, p.155 
A compreensão do sistema territorial turístico deve considerar as especificidades territoriais de dois subsistemas sociais que o constituem: o subsistema dos residentes e o subsistema dos turistas. Cada subsistema tem alguns interesses convergentes e outros antagônicos. Desta forma, cada subsistema deve ser analisado na sua particularidade e nas suas relações, buscando perceber as especificidades, dinâmicas e sobreposições (de escalas espaciais e temporais) entre os dois subsistemas (Figura 3).

\subsection{SUBSISTEMAS DE FIXOS NATURAIS}

O Subsistema de Fixos naturais se compõe de elementos cujas dinâmicas são resultantes de processos ecológicos integrantes do sistema natural, e são controlados por dinâmicas não humanas. A ação humana sob tais elementos pode perturbar suas dinâmicas, prejudicando a sustentabilidade ecológica, embora essas ações humanas possam trabalhar a favor na recuperação de sistemas perturbados, contribuindo para o princípio da sustentabilidade ecológica, pois nem sempre as ações humanas são negativas sobre o sistema natural (ANJOS, 2004).

O Município de Jaboatão dos Guararapes está localizado na Região Metropolitana do Recife, limitando-se ao Norte com a cidade do Recife e o município de São Lourenço da Mata, ao Sul com o município do Cabo de Santo Agostinho, a Leste com o Oceano Atlântico e a Oeste com o município de Moreno. Com distância aproximada de 12 quilômetros do centro da cidade do Recife.

A localização geográfica faz do Município um ponto de escoamento de produção, através do Aeroporto Internacional de Recife, os Portos de Suape em Ipojuca e do Recife e as principais vias de acesso como as Rodovias Federais BR101, que ligam o país de Norte a Sul, a BR 232 que liga a Capital ao interior do estado de Pernambuco e as Rodovias Estaduais.

De acordo com a PREFEITURA DE JABOATÃO DOS GUARARAPES (2008) o município possui uma área de 263,00 quilômetros quadrados, sendo $166,00 \mathrm{Km}^{2}$ de área urbana $(63,12 \%)$ e $97,00 \mathrm{Km}^{2}$ de área rural $(36,88 \%)$. Ao analisar a distribuição da área total do município o distrito de Jaboatão dos Guararapes aparece com a maior participação $\left(127,21 \mathrm{Km}^{2}\right)$, seguindo-se Jaboatão Centro com $\left(106,89 \mathrm{Km}^{2}\right)$, Cavaleiro $\left(15,31 \mathrm{Km}^{2}\right)$, Curado $\left(9,91 \mathrm{Km}^{2}\right)$ e Jardim Jordão com $\left(4,01 \mathrm{Km}^{2}\right)$. 


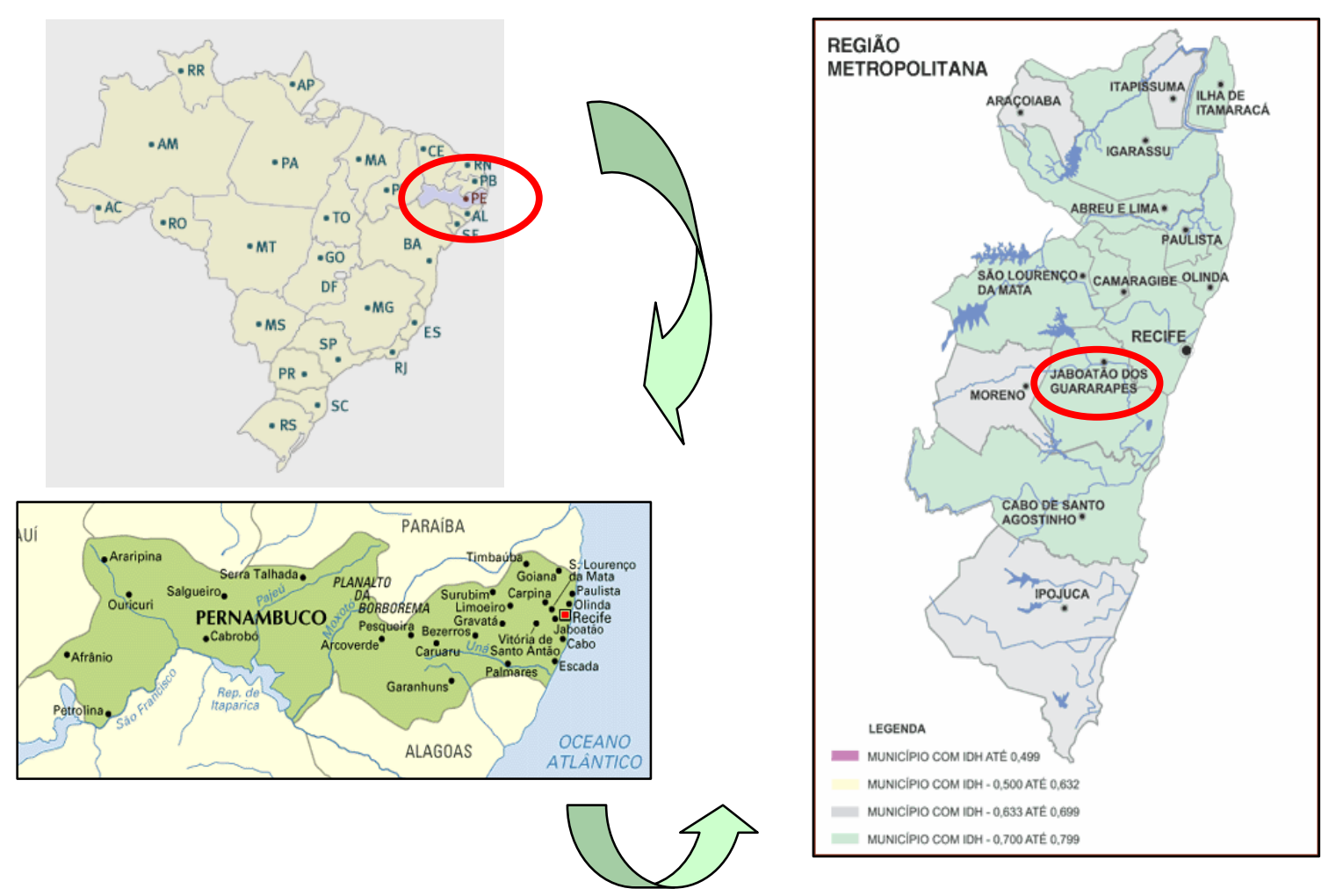

Figura 4: Mapas de Localização de Jaboatão dos Guararapes na Região Metropolitana do Recife

Fonte: CONDEPE/FIDEM (2008) /ANASPS (2008)

Com um clima quente e úmido, o município apresenta uma temperatura média de $25^{\circ} \mathrm{C}$, e a umidade relativa do ar de $82 \%$. O Perfil do relevo, do litoral para o interior é composto por uma planície costeira formada por depósitos fluviais e marinhos onde havia a restinga e atualmente recebe a expansão do mercado imobiliário, sacrificando a drenagem e provocando alagamentos nos períodos chuvosos. A elevação mais próxima fica a dois quilômetros da linha da costa com até 65 metros de altitude (CONDEPE/FIDEM, 2008; PREFEITURA DE JABOATÃO DOS GUARARAPES, 2008).

As poucas expressões dos planaltos se localizam no limite com Moreno (a oeste), conhecida como Serra da Macambira. Toda a área era ocupada pela Mata Atlântica que foi sendo derrubada para o plantio da cana-de-açúcar. No litoral há praias, manguezais, restingas e a foz do Rio Jaboatão, que se lança diretamente no Oceano 
Atlântico. Ao longo das praias há arrecifes, aflorando em um trecho da praia de Piedade chegando a formar piscinas naturais, sendo submersas na maior parte da costa.

De acordo com o Relatório Anual do Governo Municipal (2001) a vegetação nativa do município é Mata Atlântica, tipo ombrófila, dividida em arbórea, arbustiva e herbácea. Com a colonização foram trazidas fruteiras que se aclimataram bem na região e que se integraram à paisagem local, como o coco e a manga. Existem ainda às fruteiras nativas como o caju, sapoti, cajá, araçá e pitomba.

\subsection{SUBSISTEMAS DE FIXOS CONSTRUÍDOS PELO HOMEM}

De acordo com Anjos (2004) o Subsistema dos elementos construídos pelos homens, é resultante das ações humanas. O resultado dos sistemas sociais e econômicos, têm um grau de permanência diferente de outras variáveis sociais, como renda e trabalho. Os elementos construídos têm alto grau de permanência, assim, se constituem nas variáveis mais permanentes na escala própria do planejamento, ou seja, de escalas espaciais de territórios mais específicos (cidade ou lugar) e escalas temporais do homem.

O município mostra carência na sua infra-estrutura urbana, indo desde as precárias condições ambientais, com problemas nas áreas de saneamento básico, coleta e tratamento final do lixo, crescimento urbano e ocupações desordenadas, manutenção inadequada nas áreas públicas, perda na qualidade ambiental com lançamento de esgoto e lixo em canais, cursos d'água e praias com prejuízo para a drenagem e balneabilidade das praias; deficiente fiscalização ambiental, além de ineficiente sistema de transporte coletivo, com vias sem capacidade para suportar o volume de tráfego de veículos (PPA, 2005).

A ampliação e recuperação dos sistemas de drenagem existentes com ações de macro e micro-drenagem devem ser tidas como prioritárias, dada a própria situação geográfica do município e as condições dela decorrentes com o desenvolvimento de atividades de limpeza e revestimentos dos canais e drenagem em diversas áreas de estrangulamento do setor.

De acordo com dados do CONDEPE/FIDEM (2008) o setor formal de atividade econômica no ano de 2005 apresentou um total de 70.806 empregados e 9.197 
estabelecimentos, dando destaque aos setores de serviços que apresentam 20.986 empregados e 1.690 estabelecimentos; da indústria de transformação com 13.290 empregados e 881 estabelecimentos; do comércio com 12.081 empregados e 4.445 estabelecimentos; da administração pública com 8.454 empregados e 8 estabelecimentos e o setor da construção civil com 1.571 empregados e 280 estabelecimentos.

As principais atividades econômicas com valores referentes ao ano de 2000, da População Economicamente Ativa - PEA indica que, do total dos 185.262 habitantes, $42.082(22,7 \%)$ estão no comércio, reparação de veículos, objetos pessoais e domésticos; $23.351(12,6 \%)$ na indústria de transformação e 17.242 e (9,3\%) na atividade financeira, imobiliária, de aluguéis e prestadora de serviços (CONDEPE/FIDEM, 2008).

O turismo se mostra como um fator econômico bastante expressivo no município. Além das praias, apresenta atividades ligadas a esportes radicais, lazer, cultura, gastronomia, artesanato e potencialidade voltada a áreas rurais (EMPETUR, 2002).

No que se refere ao sistema de saneamento, os dados do ano 2000, fornecidos pela CONDEPE/FIDEM (2008) apresentam as formas de abastecimento de água dos domicílios num total de 150.358 domicílios, sendo 119.076 domicílios $(79,2 \%)$ ligados à rede geral; 19.623 domicílios $(13,1 \%)$ ligados a poço ou nascente e 11.659 domicílios $(7,8 \%)$ ligados a outras formas não especificadas. Os domicílios com banheiro ou sanitário se apresentam num total de 143.370 (95,4\%); sendo ligados à rede geral apenas 31.751 domicílios $(22,1 \%)$ e não ligados à rede geral 6.988 domicílios $(7,9 \%)$.

Ao mencionar o destino dado ao lixo com valores referenciais ao ano 2000 verifica-se que num total dos 150.358 domicílios, o lixo é coletado em 108.244 domicílios, e recebe outros destinos nos 42.114 domicílios. Em se tratando da distribuição da energia elétrica com valores referentes ao ano de 2006, num total de 177.846 consumidores, às formas de abastecimento apresentam-se distribuídas em 165.695 por residência, 627 pelas indústrias, 10.830 pelo comércio, 142 na área rural, 471 pelo poder público, 29 pela iluminação pública e 52 de outras formas (CONDEPE/FIDEM, 2008). 


\subsection{SUBSISTEMAS DE FLUXOS SÓCIO-CULTURAIS}

Conforme elucida Anjos (2004) o Subsistema dos fluxos sócio-culturais é composto de dinâmicas imprevisíveis e bastante complexas. Isso ocorre devido ao envolvimento da relação do homem com os sistemas ecológicos, econômicos e o próprio sistema social.

Dados do Relatório Anual do Governo Municipal (2001) mostram que a partir de 1940, o município apresentou um acelerado processo de adensamento demográfico, com elevadas taxas de crescimento, o que superou a sua capacidade de oferecer condições de emprego, infra-estrutura física e equipamento de lazer, resultando em agravamento da qualidade de vida da população ao longo dos anos.

A organização sócio-espacial de uma localidade se faz presente, devido a um conjunto de fatores, físicos, sociais e ambientais. Esses fatores definirão os futuros processos de utilização de um dado espaço.

A contextualização dessa dinâmica define o espaço em relação a uma sociedade. Esse conceito é compreendido por Santos (1997b, p. 50) ao definir que a estrutura implica na inter-relação das partes de um todo, mediante o modo como se organizam; o processo determina uma ação contínua que se desenvolve em direção a um resultado; a função indica uma tarefa ou atividade esperada de uma forma, pessoa, instituição ou coisa e a forma se manifesta como um de seus aspectos num dado instante do tempo.

De acordo com a PREFEITURA DE JABOATÃO DOS GUARARAPES (2008) o município de Jaboatão dos Guararapes atualmente apresenta uma divisão territorial bastante definida, dividido em cinco distritos:

No Primeiro Distrito - Jaboatão dos Guararapes: situa-se a orla marítima, constituída pelas praias de Venda Grande, Piedade, Candeias e Barra de Jangada com 7 Km de extensão. Apresenta erosão provocada pelo mar, aguçada pela ação do homem, construções de muros de arrimo, aterros, altos prédios e ocupações desordenadas e irregulares. A crescente expansão urbana nas praias, sem o devido controle urbanístico e ambiental, resulta numa visível deterioração do patrimônio natural.

Também se faz presente um pólo industrial em situação de degradação, porém com potencialidades para alojar novas atividades industriais devido à facilidade de 
escoamento e produção através da rodovia federal (BR101), dos Portos de Suape e do Recife e do Aeroporto Internacional do Recife. Ainda nesse distrito está o Parque Histórico Nacional dos Guararapes, tombado pelo IPHAN $^{1}$ por se tratar de um patrimônio de cunho histórico-cultural.

O segundo Distrito - Jaboatão Centro: apresenta ainda características de cidade interiorana com sua população dedicada ao comércio e à agricultura. Predominam as habitações populares e antigas. $O$ sistema de transporte é complementado pela Rodovia Federal BR 232 e PE 007, vias férreas, com metrô ${ }^{2}$ de superfície e trem de carga.

O terceiro Distrito - Cavaleiro: tem sua origem ligada ao pequeno comércio, procedente da Feira de Cavaleiro. Atualmente a Feira de Cavaleiro é o maior centro de abastecimento do município. Teve sua consolidação com a implementação do Núcleo Industrial do Curado que possui diversas indústrias de médio e grande porte e do Conjunto Habitacional Curado I.

O quarto Distrito - Curado: foi desmembrado do terceiro Distrito em dezembro de 1996, compreende todo território ao Norte da BR232. Nesse Distrito encontram-se grandes Conjuntos Habitacionais como o Curado II, III e IV, da extinta COHAB e parte do Distrito Industrial do Curado.

O quinto Distrito - Jardim Jordão: predomina a ocupação residencial com algumas indústrias e significativo comércio de veículos e material de construção.

Para Santos (1997a), o aumento da população total, da população urbana e da população industrial não se deve à influência do movimento próprio de parcelas localizadas nas diferentes regiões, mas ao movimento global decorrente das forças mais gerais responsáveis pela distribuição geográfica das diversas variáveis sobre o conjunto.

Jaboatão dos Guararapes apresentou um aumento população de 200.975 habitantes para 487.119 habitantes num período de 20 anos (1970-1991), mantendo a taxa elevada de crescimento, no ano de 2000 a população era de 581.556 habitantes, já no ano de 2007 a população era de 665.387 habitantes (CONDEPE/FIDEM, 2008; IBGE, 2008).

Perfazendo uma evolução populacional da ordem de $478 \%$ em 30 anos. Os dados mostram que 568.474 habitantes $(97,75 \%)$ da população vivem na área urbana,

\footnotetext{
${ }^{1}$ Instituto do Patrimônio Histórico Nacional.

${ }^{2} \mathrm{O}$ metrô do Recife possui uma linha-tronco que interliga Recife ao centro de Jaboatão.
} 
com destaque para a ocupação vertical da orla marítima, refletindo uma altíssima taxa de urbanização. Tais processos acarretando formas de urbanização anárquica, assim considerado pelo Relatório Anual do Governo Municipal (2001). A ausência de planejamento da cidade tem tornado a forma de ocupação do espaço urbano bastante crítico.

Os grandes processos de ocupação ocorridos algumas vezes em áreas insalubres, não apresentam infra-estrutura urbana, como saneamento básico, drenagem $\mathrm{e}$ pavimentação. Este crescimento caracteriza o município como receptor de população, pelo que, de acordo com o CONDEPE/FIDEM (2008), constata-se uma densidade demográfica de 2.271,10 hab./km², bem maior que a média do Estado de Pernambuco 80,30 hab. $/ \mathrm{km}^{2}$.

Apesar de todo esse processo de ocupação e organização o município apresenta uma área litorânea com potencial para o turismo, oferecendo hospedagem tanto para quem pretende visitar o próprio município, quanto para quem busca cidades que ficam num raio de atuação, como Recife, Olinda e Ipojuca. A busca por lazer, cultura, gastronomia e artesanato, também são fatores expressivos no interesse da visitação.

No turismo cultural, o município apresenta um grande acervo de bens culturais como igrejas, engenhos, usinas e casarios que remetem a época colonial, constituindo-se num patrimônio cultural. Neste acervo de vários monumentos arquitetônicos destacamse: o Parque Histórico Nacional dos Guararapes, engenhos e casas grandes, casa da cultura, mercado público e igrejas presentes no município.

Essa variedade cultural apresenta-se permeada pela diversificação dos produtos artesanais, das danças folclóricas, dos festejos populares, dos clubes e das troças. Essas potencialidades podem ser aproveitadas em benefício econômico para a população local.

\subsection{SUBSISTEMAS DE FLUXOS ECONÔMICOS}

Conforme cita Anjos (2004) o Subsistema dos fluxos econômicos é composto por dinâmicas relacionadas à produção, distribuição, consumo e acumulação do capital. Tal subsistema se apresenta formado por um conjunto de organizações que atuam, tanto para atender o residente, como o turista. As organizações empresariais que diretamente 
atendem o turista podem ser reunidas em empresas que atuam nos serviços de hospedagem, de alimentação, de lazer e entretenimento, de agenciamento e de transporte.

Ao analisar o município de Jaboatão dos Guararapes observam-se os sinais da modernização na economia que se fez presente nas mudanças da produção econômica (ARAÚJO, 1988).

Nas primeiras décadas do século XX a modernização modificou a estrutura do sistema agrário e conseqüentemente as relações de poder. $\mathrm{O}$ município alterou sua base econômica a partir da instalação de fábricas destinadas ao ramo de indústria de alimentos e papel, resultando nas mudanças sociais como o incremento populacional pela migração, o aumento do número de indústrias e a especulação imobiliária (ANDRADE, 1995).

A urbanização intensa de Jaboatão tem na ampliação da base econômica local um de seus determinantes. O fato de fazer parte da Região Metropolitana do Recife RMR facilita o escoamento da produção industrial por meio das vias de acesso (porto e aeroporto), esse dinamismo possibilita o crescimento do município, refletindo nas suas atividades econômicas. O Município também se mostra como o terceiro maior PIB do Estado em estabelecimento de indústrias de transformação e o segundo maior nos serviços de comércio atacadista de alimentos e bebidas (CONDEPE/FIDEM, 2008).

Trata-se de uma economia dinâmica com presença de vários tipos de atividades econômicas. A consequiência do processo de industrialização ocorrida nos últimos 30 anos colocou Pernambuco como o Estado do Nordeste que tem a maior diversificação fabril da região. O crescimento industrial do município de Jaboatão foi beneficiado em virtude da sua localização estratégica e facilidade de suprimento de matéria-prima, distribuição e comercialização do produto final, estruturando-se como pólo industrial.

Destacam-se também a agricultura e pecuária devido a sua importância histórica e significativa na economia do município. Dados do CONDEPE/FIDEM (2008) revelam que no ano de 2005 o setor terciário gerou $76 \%$ do total de empregos da economia metropolitana. Para as atividades agrícolas, foi apontado o monopólio da cana-de-açúcar e o cultivo de coco, banana, inhame, mandioca, acerola e maracujá. Já na atividade pecuária, o efetivo teve maior representatividade na criação de frango seguido por suínos e bovinos. 
O município também se mostra expressivo economicamente no turismo por possuir cadeias hoteleiras de grande relevância e de nível internacional. Distribuídos em hotéis, apart hotéis, flats e pousadas com aproximadamente 1.580 leitos e 1.019 unidades habitacionais (Uhs) preparados para receber turistas do Brasil e do exterior (EMPETUR, 2002).

Para o transporte aéreo de passageiro, Jaboatão utiliza-se do Aeroporto Internacional dos Guararapes. A cidade usa o terminal integrado de passageiro (TIP) juntamente com o Recife, que está localizado no bairro do Curado, no município de Jaboatão dos Guararapes. O metrô que interliga Jaboatão velho ao bairro do Recife, possui estações modernas e bem cuidadas. O trem que faz o trajeto de Prazeres ao Cabo é usado para o transporte de passageiros, já o que faz o percurso de Prazeres a Jaboatão Velho é utilizado para transportar cargas (PPA, 2005).

A infra-estrutura de apoio está representada pelos centros de negócios, comércio e serviços, shopping center, galerias, feiras, parques, praias, bares, restaurantes, lanchonetes, sorveterias, cinemas, teatros, biblioteca, igrejas, museus, espaços culturais, usinas e engenhos. Segundo dados da Empetur (2002) a oferta dos meios de hospedagem da RMR por ordem de maior número de leitos, apresentam-se mais expressivos em Recife, Ipojuca, Olinda e Jaboatão dos Guararapes.

\section{CONSIDERAÇÕES FINAIS}

O trabalho buscou compreender o sistema territorial turístico do município de Jaboatão dos Guararapes, a partir da análise dos subsistemas de fluxos e fixos que envolvem, os elementos naturais e construídos pelo homem e as dinâmicas sócioculturais e econômicas (ANJOS, 2004).

A partir da aplicação deste modelo de análise observaram-se vantagens no município de uma maneira ampla, permitindo a avaliação dos fatores naturais, construídos, econômicos e sócio-culturais de forma integrada.

A análise permitiu identificar que o município possui a segunda cidade mais importante do estado em termos de desenvolvimento industrial e PIB, demonstrando novas possibilidades econômicas ligadas principalmente à sua localização, por ser 
favorável à instalação de novas indústrias. $\mathrm{O}$ fato de o seu parque industrial estar às margens da BR101; da proximidade com o aeroporto internacional e com o maior porto de Pernambuco (Suape) facilita o escoamento da produção e o recebimento de matériaprima. Do mesmo modo essas vias de acesso servem ao turismo, os principais pólos turísticos de Pernambuco; Ipojuca e Recife estão localizados em posição estratégica.

Porém, com todo este potencial o município enfrenta vários problemas sociais, o crescimento habitacional foi muito rápido e a falta de infra-estrutura básica do município que não conseguiu acompanhar o crescimento, acarretando a falta de saneamento, escolas, pavimentação entre outros. O município depende da infra-estrutura de acesso do Recife (metrô e aeroporto) e de Ipojuca (porto). Isso deixa claro que em alguns momentos a cidade de Jaboatão não passa de uma extensão da capital, desvalorizando assim sua identidade e seu valor pela sua cultura, dificultando a constituição de um território turístico.

Devido a esta problemática, o turismo não é devidamente tratado no município, ligado tanto à falta de infra-estrutura e do incentivo do poder público municipal. $\mathrm{O}$ município passa uma imagem para o turista de cidade dormitório, onde ficam bons hotéis que servem apenas para dar suporte aos principais pontos turísticos do estado, que estão localizados nas cidades de Recife, Olinda e nas praias do litoral Sul.

As premissas do planejamento do espaço turístico de Jaboatão dos Guararapes precisam se ater aos limites e possibilidades levantadas, promovendo um processo participativo de planejamento e gestão, que aproveite o potencial existente, quer seja de belezas naturais ou de riquezas históricas, que ao mesmo tempo contribui para a justiça social e um desenvolvimento ecológico equilibrado tanto para os turistas quanto para a população local.

\section{REFERÊNCIAS}

ANASPS - Associação Nacional dos Servidores da Previdência Social. Mapa do Estado de Pernambuco. Disponível em: http://pe.anasps.org.br/index.asp?link=18. Visitado em: 17 de jan. 2008.

ANDRADE, A. L; SElMA, A; RODRIGUES, L. H; SOUTO, R. Pensamento sistêmico: caderno de campo: o desafio da mudança sustentada nas organizações e na sociedade. Porto Alegre: Bookman, 2006. 
ANDRADE, M. C. Pernambuco Imortal. Recife: Jornal do Comércio, 1995.

ANJOS, F. A. dos. Processo de Planejamento e Gestão de Territórios Turísticos: uma proposta sistêmica. [Tese de Doutorado, apresentado ao programa de pósgraduação em Engenharia de Produção da Universidade Federal de Santa Catarina]. Florianópolis, 2004.

ARAÚJO, O. B. Jaboatão: sua terra e sua gente. Jaboatão: Fundação Yapoatan, 1988.

CAPRA, F. As conexões ocultas: Ciências para uma vida sustentável. Tradução: Marcelo Brandão Cipolla. São Paulo: Cultrix, 2002.

CONDEPE/FIDEM - Agência Estadual de Planejamento e Pesquisa de Pernambuco. Perfil Municipal de Jaboatão dos Guararapes. Disponível em: < http://www.condepefidem.pe.gov.br/perfil_municipal/municipios.asp?cod=6>. Acesso em: 05 de Mai. 2008.

EMPETUR - Empresa Brasileira de Turismo de Pernambuco. Oferta dos Meios de Hospedagem da Região Metropolitana do Recife (Abril/2002), Pesquisa do Inventário da Oferta Turística de Pernambuco.

IBGE - Instituto Brasileiro de Geografia e Estatística. Perfil dos Municípios. Disponível em: < http://www.ibge.gov.br> Acessado em 06 de Mai. de 2008.

PANOSSO NETTO, A. Filosofia do turismo: teoria e epistemologia. São Paulo: Aleph, 2005.

PPA - PLANO PLURIANUAL. Município de Jaboatão dos Guararapes (20062009). Prefeitura Municipal de Jaboatão dos Guararapes: Jaboatão dos Guararapes, 2005.

PREFEITURA DE JABOATÃO DOS GUARARAPES. Perfil da Cidade. Disponível em:<http://www.pjg.com.br/index.php?opcao=6> Acessado em: 05 de Mai. 2008.

RELATÓRIO ANUAL DO GOVERNO MUNICIPAL. Município de Jaboatão dos Guararapes. Prefeitura Municipal de Jaboatão dos Guararapes: Jaboatão dos Guararapes, 2001.

RODRIGUES, A. B. Turismo e espaço: rumo a um conhecimento transdisciplinar. São Paulo: Hucitec, 1997.

RUSCHMANN, D. V. M. Turismo e planejamento sustentável: a proteção do meio ambiente. 11 ed. Campinas: Papirus, 2004

SANTOS, Milton. A natureza do espaço. São Paulo: Hucitec, 1997a.

Espaço e método. 4. ed. São Paulo: Nobel, 1997b. 
SANTOS, M; SILVEIRA, M. L. O Brasil: território e sociedade no início do século XXI. 7. ed. Rio de Janeiro: Record, 2005.

SCHÄFER, K. L.; ANJOS, F. A. dos. Aplicação do modelo de planejamento e gestão territorial turística em destinos em consolidação: O caso de Porto Belo. In: VI Seminário de Iniciação Científica, 2007, Univali: Itajaí. Anais do livro de resumos do VI Seminário de Iniciação Científica, out. 2007.

TELES, R. M. de S. A importância do território na prática do planejamento turístico - reflexões acerca do Brasil. In RUSCHMANN, D. V. M. e SOLHA, K. T. (orgs.) Planejamento Turístico. Barueri: Manole, 2006.

Recebido em: 22 de janeiro de 2008

Aprovado em: 22 de fevereiro de 2008 